\title{
Rare diseases: past achievements and future prospects
}

\author{
Birute Tumiene $^{1,2} \cdot$ Ulf Kristoffersson $^{3} \cdot$ Victoria Hedley $^{4} \cdot$ Helena Kääriäinen $^{5}$ \\ Published online: 4 May 2021 \\ (C) The Author(s), under exclusive licence to Springer-Verlag GmbH Germany, part of Springer Nature 2021
}

Rare diseases (RD), according to the EU-definition set down by the Regulation on Orphan Medicinal Products (Regulation (EC) No 141/2000) are conditions affecting fewer than 5 in 10,000 newborns. The vast majority of the more than 6000 unique RD currently registered in the Orphanet database have a point prevalence of less than $1 / 1000000$ inhabitants (Nguengang Wakap 2020). This rarity and the sheer number of conditions classed as rare, together with other features that are typical for a majority of rare diseases - their chronic, frequently disabling nature, heterogeneous multisystem involvement and complexity in diagnostics and treatment create unique challenges to our care systems.

Neglect of these challenges may incur a huge price for approximately 30 million patients and their families in the EU and evolve into unacceptably long diagnostic oddysseys and labyrynths, unwarranted inequities in access to scarce RD treatments, and a huge burden of complex care coordination that lies onto the shoulders of patients and their families, causing them many personal, professional, and social life difficulties and diminishing their quality of life (Rare Barometer 2017). In this Special Issue, we would like to provide you with a series of inspiring historical perspectives on $\mathrm{RD}$, outlining of patient-centered, integrated and collaborative approaches to $\mathrm{RD}$, as well as expert opinion pieces assessing the status quo and highlighting important future trends that involve such

Birute Tumiene

tumbir@gmail.com

1 Institute of Biomedical Sciences, Faculty of Medicine, Vilnius University, Vilnius, Lithuania

2 Vilnius University Hospital Santaros Klinikos, Vilnius, Lithuania

3 Division of Clinical Genetics, Laboratory Medicine (U.K.), Lund University, Lund, Sweden

4 John Walton Muscular Dystrophy Research Centre, Newcastle University, Institute of Genetic Medicine, Newcastle upon Tyne, UK

5 Genomics and Biomarkers Unit, National Institute for Health and Welfare, Helsinki, Finland cutting-edge breakthroughs as genomic diagnostics, screening across the life cycle and curative gene therapies.

Inevitably, robust solutions to RD challenges involve a vast range of stakeholders across several sectors in society such as health and social care, education and research, and require robust national and international collaboration. Putting RD onto EU and national policy maps became a priority during the last two decades and provided crucial legal frameworks and strategies, the implementation of which was encouraged by EU expert groups and joint actions and eventually put into day-to-day practice by such pan-European collaborations as the European Joint Programme on Rare Diseases (EJP RD) and European Reference Networks (ERNs). Concurrently, National Plans and Strategies (NP/NS) on RD were adopted in 27 out of $30 \mathrm{EU}$ and European Economic Area (EEA) countries. The heterogeneous approach taken by different countries in elaborating and implementing these NP/NS is outlined in by Hedley et al. (2021), along with concerns over the future of these essential national policies. As no single country can solve RD-related problems alone, ERNs should provide an exceptionally high added value and economies of scale, scope and speed. However, being worldwide pioneers, ERNs have naturally been confronted with some unexpected and still unresolved issues that may preclude reaping their full benefits and jeopardize their long-term sustainability (Tumiene et al. 2021).

In the era of ERNs, RD care pathways stretch out not only across entire national systems, but also cross the borders, injecting an additional layer of complexity onto the inherently challenging task of ensuring a patient-centered, coordinated and integrated approach to RD care; specificities of RD care pathways were described by Tumiene and Graessner (2021). As clearly stated by Bolz-Johnson et al. (2021) in their paper, the role of patient organizations and patients has always been special and unique in the RD field and will be even more so in the future; indeed, our patients remain our greatest - and still largely untapped - resource, and must be leaders, experts and partners across a broad range of activities to eventually lead to meaningful progress in the RD field. 
More than $70 \%$ of $\mathrm{RD}$ are genetic in nature, hence the importance of our recent breakthroughs in genomics and gene therapies. With the introduction of next generation sequencing (NGS) technologies, diagnosis is not anymore a daunting task for a lone devoted doctor, but rather an exercise in teamwork between the medical professionals and the laboratory specialists, empowered by many open-source, worldwide databases and tools (Vinkšel et al. 2021).

As described by Maldonado and Jalil (2021), curative gene therapies will eventually bring long-awaited hope to many thousands of RD patients and their families. Technological developments, both treatment-driven and test-driven, will most probably reshape our attitudes towards screening for genetic diseases across the life cycle, including neonatal and carrier testing (Cornel et al. 2021). Altogether, these breakthroughs will inevitably transform the future genetics clinic and its role in overall healthcare provision, building bridges between rare and common diseases and shifting the focus towards genetic data-based diagnosis and prevention (Vrijenhoek et al. 2021).

In spite of all this progress, diagnosing, treating and caring for patients with RD is not a straightforward task and will probably never be as streamlined or organized as for common disorders, where guidelines, treatment programmes and development of new drugs ensure easy methods of systematic information collection which support ongoing improvements. However, with the advent of personalized and precision medicine, healthcare is becoming more and more patient-centered and individualized. That can be as simple as monitoring CYPgene variants to identify the speed of metabolizing a specific drug to tracing or molecular characterizing of tumor cells, or performing presymptomatic screening for disease-associated variants in your genome. All these investigations will reveal individuals who fall out of the mainstream of common disorders and need special attention and expertise, sometimes called the "New Orphans'. Therefore, what we now learn from investing in knowledge on RD will be of great importance for how we will handle the diagnosis and treatment of common disorders in the near future.

In this Special Issue we aim to describe the status quo pertaining to RD in today's Europe, reflecting on how we have reached our current vantage point, whilst offering glimpses into possible future trends. Even though the focus is on the European situation, many experiences can be generalized globally.

\section{References}

Bolz-Johnson M, Kenny T, Le Cam Y, Hernando I (2021) Our Greatest, Untapped Resource: Our Patients. J Community Genet

Cornel MC, Rigter T, Jansen ME, Henneman L (2021) Neonatal and carrier screening for rare diseases: how innovation challenges screening criteria worldwide. J Comm Genet. https://doi.org/10. 1007/s12687-020-00488-y

Hedley V, Bottarelli V, Taruscio D, Weinman A (2021) Shaping national plans and strategies for rare diseases in Europe: past, present and future. J Community Genet

Maldonado R, Jalil S (2021) Wartiovaara K Curative gene therapies for rare diseases. J Community Genet. https://doi.org/10.1007/s12687020-00480-6

Nguengang Wakap S, Lambert DM, Olry A, Rodwell C, Gueydan C, Lanneau V, Murphy D, Le Cam Y, Rath A (2020) Estimating cumulative point prevalence of rare diseases: analysis of the Orphanet database. Eur J Hum Genet 28:165-173. https://doi.org/10.1038/ s41431-019-0508-0

Rare Barometer (2017) Juggling care and daily life: the balancing act of the rare disease community. Available at: http://download2. eurordis.org.s3.amazonaws.com/rbv/2017_05_09_Social\% 20survey\%20leaflet\%20final.pdf

Tumiene B, Graessner H (2021) Rare disease care pathways in the EU: from odysseys and labyrinths towards highways. J Community Genet. https://doi.org/10.1007/s12687-021-00520-9

Tumiene B, Graessner H, Mathijssen IM et al (2021) European reference networks: challenges and opportunities. J Community Genet. https://doi.org/10.1007/s12687-021-00521-8

Vinkšel M, Writzl K, Maver A, Peterlin B (2021) Improving diagnostics of rare genetic diseases with NGS approaches. J Community Genet. https://doi.org/10.1007/s12687-020-00500-5

Vrijenhoek T, Tonisson N, Kääriäinen H, Leitsalu L, Rigter T (2021) Clinical genetics in transition - a comparison of genetic services in Estonia, Finland, and the Netherlands. J Community Genet. https:// doi.org/10.1007/s12687-021-00514-7

Publisher's note Springer Nature remains neutral with regard to jurisdictional claims in published maps and institutional affiliations. 